\title{
Study on early warning of rapid sinking of large land caisson in silt layer
}

\author{
Shi zhangru ${ }^{1,2,3}$, Liang Xiaoteng ${ }^{1}$, He Zuhao ${ }^{1}$, Qiu Min ${ }^{1}$ \\ ${ }^{1}$ CCCC Second Harbour Engineering Co. Ltd, Wuhan \\ ${ }^{2}$ Key Laboratory of Transportation Industry for Construction Technology of Long Bridge, Wuhan \\ ${ }^{3}$ Intelligent Construction Technology Centre for Transportation Infrastructure, Wuhan
}

\begin{abstract}
Large caisson constructed in the soft soil layer is prone to rapid sinking during the sinking process. Rapid sinking is often accompanied by partial sinking, which affects construction safety and subsequent construction. There is no relevant early warning mechanism for early warning of rapid sinking. This paper takes the sinking construction of a large land caisson in a deep silt layer as an example, analysis the rapid sinking mechanism through the earth pressure and settlement rate of the sinking process, and proposes a rapid sinking early warning mechanism. Before the rapid sinking, the soil at the edge of the blade feet is partially plastic damaged, and the earth pressure decreases continuously after reaching its limit value; The strain softening of the overlying soft soil layer, the rapid reduction of side friction and the instability of open caisson caused by soil gushing after the plastic zone connecting are the important reasons for the rapid sinking. The rapid sinking process is divided into "sagging section, starting section, instability section and stable section". The earth pressure early warning mechanism is the continuous decrease of the earth pressure at the blade feet. When the sinking rate exceeds the threshold value for two hours, it is regarded as the early warning mechanism of sinking rate. Using this dual control mechanism of end earth pressure and sinking rate can effectively warn the rapid sinking of the caisson.
\end{abstract}

\section{Introduction}

With the development of long-span bridges, the caisson, as the foundation, is developing in the direction of large size, multi compartment and more complicated geology. Large scale open caisson has large span, more sinking times, longer construction period and higher construction control difficulty. Especially in soft soil stratum, the uneven distribution of soft soil and thixotropy of soft soil easily leads to partial sinking, stagnant sinking and rapid sinking. The large tilt that occurs after rapid sinking makes it more difficult to adjust the attitude of the caisson ${ }^{[1]}$.

Many scholars have studied the subsidence control of large open caisson. Chang Dabao ${ }^{[2]}$ studied the difficulties encountered in the construction of several large caissons and their solutions; pointed out that the weight ratio of open caisson should be increased properly in the design of open caisson, and the reasonable setting of sinking aid measures are the key to make it smooth sinking. He Qiaoling et al. ${ }^{[3]}$ based on the monitoring data of the earth pressure on the side wall of the South Anchorage caisson of Taizhou Yangtze River Bridge, analysed the variation law of the earth pressure on the side wall of the caisson. The research of the ultimate bearing capacity and side friction resistance of the caisson blade feet soil is quite abundant ${ }^{[4-6]}$. Existing researches mainly focuses on the structural stress, the ultimate soil resistance of the blade feet, and the friction resistance of the side wall. While the research depth is insufficient in the aspect of the control means of caisson sinking, which has guiding significance for the construction. Sinking of open caisson is a process in which own weight overcomes buoyancy, friction between shaft wall and soil, and resistance of soil under the blade feet. The soil under the blade feet surface is destroyed first, and the slope of the blade feet compresses the soil to move to the inner side of the caisson ${ }^{[7]}$. The key to the sinking of open caisson is to control the external friction, the end resistance of the soil under the partition wall and blade feet. Studies have shown that the depth of blade is an important factor affecting the ultimate soil resistance ${ }^{[8]}$.

After the large caisson appears stagnant, the deep bottom of the pot will easily lead to rapid sinking; when the mud surface and stratum are unevenly distributed, it is often accompanied by deflection, the height difference of the four corners and the centre offset increases, and even exceed the design allowable value. After a large tilt, there is a structural contradiction between the sinking and the attitude control, which makes the control of the smooth sinking of the caisson extremely difficult. Monitoring technologies continue to develop and are gradually applied to the sinking control of the caisson; which mainly includes the attitude of the caisson and the structural stress. It is not yet possible to analysis the

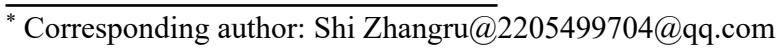


subsidence risk early, and there are few related papers on the rapid subsidence combined with the engineering case analysis. Based on the sinking construction of an anchor caisson foundation of a suspension bridge, this paper studies the rapid settlement early warning analysis based on monitoring data, discusses the rapid sinking mechanism, and provides a reference for similar projects.

\section{Project overview}

The south anchor caisson foundation of a suspension bridge is the first large-scale land caisson constructed with a deep silt layer. The plane size is $70 \times 63$ miters $(\mathrm{m})$ and the total height is $67.5 \mathrm{~m}$. There are 30 rectangular wells $(10.84 \times 10 \mathrm{~m})$ in total. Except for the steel shell concrete caisson in the first section, the rest are reinforced concrete caisson. The process of "three times of height connection, three times of sinking" was adopted to complete the height connection and sinking of the caisson.

The upper part of geological section is Holocene alluvial and marine deposits, marine muddy clay mixed with silt, muddy clay, etc., with a thickness about $33.6 \mathrm{~m}$, which has the characteristics of high compressibility, easy disturbance and deformation, and low bearing capacity. Marine clay and alluvial marine silt are distributed in the middle of the area, with poor engineering properties. The top elevation of pebble layer is $-58.81 \sim-60.91 \mathrm{~m}$, which is the designed base bearing stratum.

\section{General situation of rapid sinking of caisson}

\subsection{First rapid sinking}

Before the rapid sinking, the caisson was stagnant, and only the last section wasn't connected to the height. The air curtain made a poor drag reduction effect. The strategy of gradually sucking mud to weaken the end soil support was adopted to make it sink. On July 22, 2019, the caisson sank rapidly for the first time. During the rapid sinking process, the caisson sank sideways, the height difference of the four corners and the bottom position increased rapidly, the surface of the caisson sank obviously, and the soil gushed into the cabin about $8756 \mathrm{~m}^{3}$, with the mud surface in the cabin rising by an average of $3.92 \mathrm{~m}$.

\subsection{The second rapid sinking}

After the first rapid sinking and partial settlement, the upstream side was relatively high, the blade feet entered the clay and silt layer, while the downstream blade feet entered the cohesive soil silt layer; the key point of the subsidence control was adjusted from "sinking with taking soil" to "correct deviation as the main and subsidence as a supplement". Besides, the strategy of "taking more mud on the high side and less mud on the low side" was adopted to gradually increase the depth of the pot on the upstream side and control the depth of the blade feet. In the process of gradual weakening of the support, the average sinking was 0.1 centi-meter per day $(\mathrm{cm} / \mathrm{d})$, and the caisson was still in a stagnant state, so dewatering was used to reduce floating and assist sinking. The second rapid sinking occurred after the water level in the tank was lowered to $-7.0 \mathrm{~m}$ on September 26, 2019. The upstream changed from the high side to the low side, and the bottom position was adjusted back to within the design allowable range, but the inclination further increased.

The two rapid sinking were accompanied by partial sinking, and the surrounding soil poured into the wells. The paper ${ }^{[1]}$ points out that there may be two reasons for rapid sinking or soil gushing. One is that the hydraulic gradient at the blade feet of open caisson is too large due to too fast suction speed; The second is that the void at the blade feet is too high and the buried depth is insufficient, which leads to the collapse of the soil under the action of gravity. Plastic failure occurred in the soil at the blade feet, and the loss of bearing capacity resulted in the instability of the caisson, which can be analysed through monitoring data.

\section{Monitoring data analysis}

\subsection{Soil pressure}

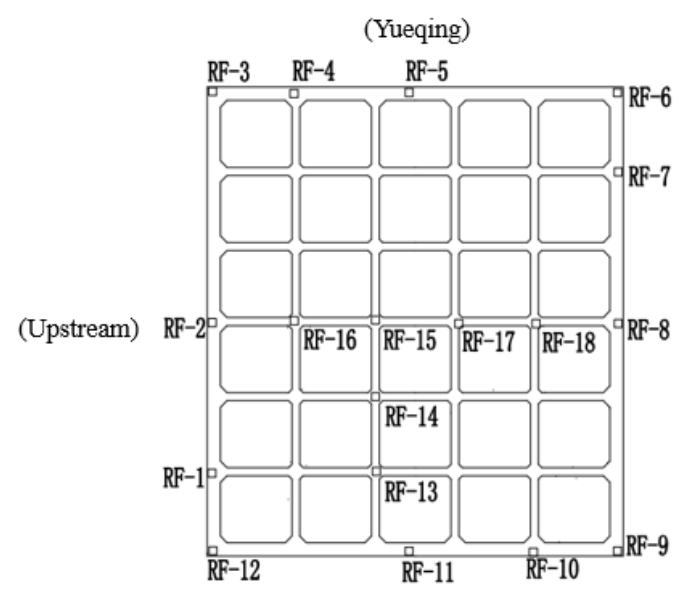

Figure 1. Arrangement of earth pressure gauge at the bottom of caisson.

Figure 1 shows the arrangement of measuring points for earth pressure at the end. The change curve of water level (difference in water head inside and outside, $\Delta w$ ), mud surface support area $\left(A_{m}\right)$ and earth pressure before the first rapid sinking is shown in figure 2 , and the change of earth pressure before the second rapid sinking is shown in figure 3 . In the stagnation stage before the first rapid subsidence, the average earth pressure at RF-3, RF-9, and RF-12 points was $2.19 \mathrm{MPa}$, and the average ultimate earth pressure was $2.73 \mathrm{MPa}$. Except for the monitoring points at the corner points (hereinafter referred to as the edge points), the average earth pressure in the stagnation stage was only $0.65 \mathrm{MPa}$, and the average ultimate soil resistance was $0.68 \mathrm{MPa}$. The average of earth pressure at the corner points before the 
second rapid subsidence was $1.53 \mathrm{MPa}$, while the average pressure at the edge point soil was $0.66 \mathrm{MPa}$. The limit soil resistance of corner points was obviously greater than that of edge points, the use of edge points for monitoring would underestimate the earth pressure and its changes.

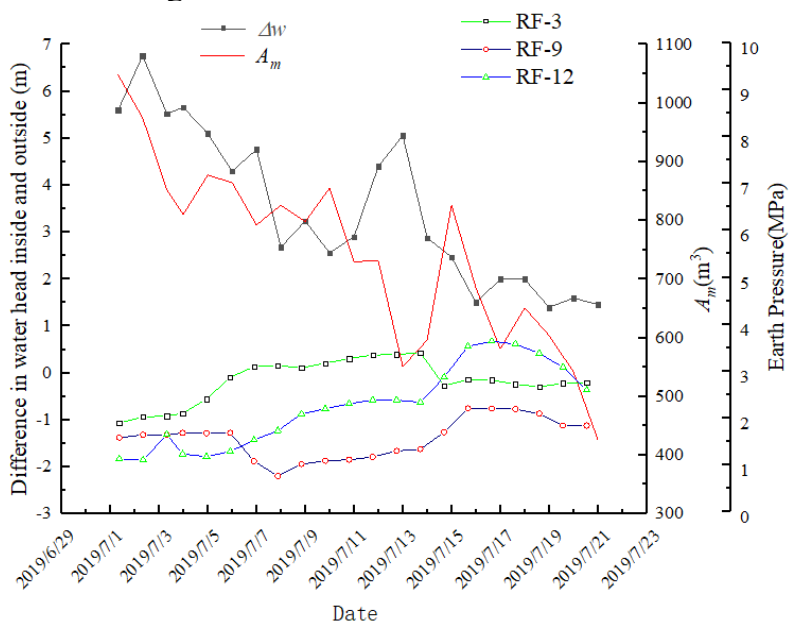

Figure 2. Change curve of supporting area, water level and earth pressure.

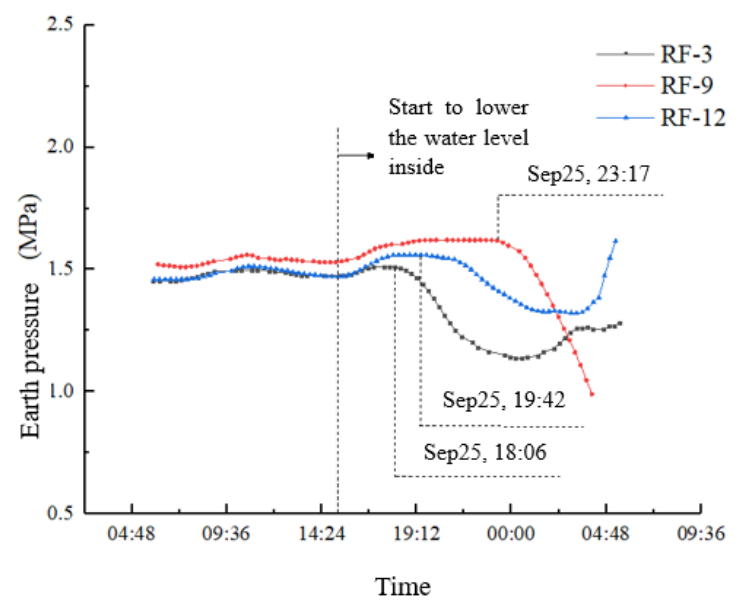

(a) Change curve of earth pressure in corner point.

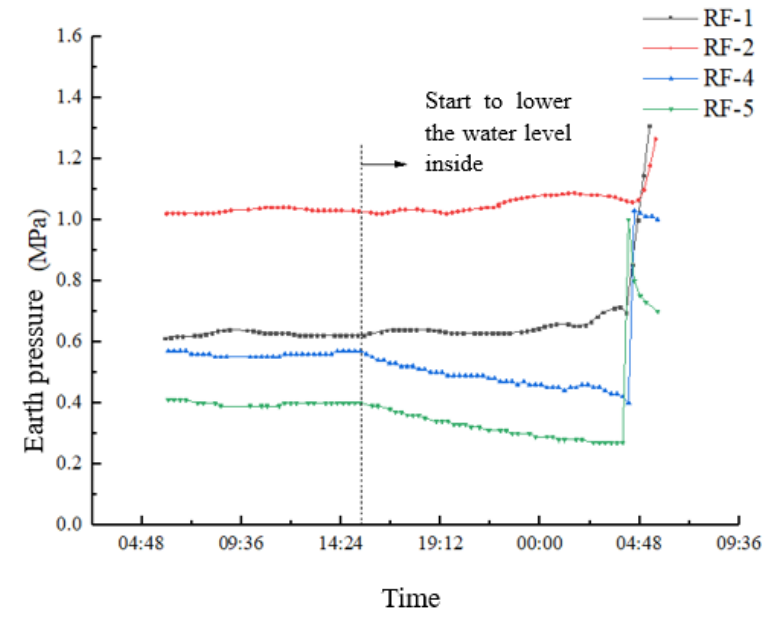

(b) Change curve of earth pressure in edge point.

Note: Data from 06:00 on September 25th to 06:00 on September 26th.

Figure 3. Earth pressure in the second rapid sinking.
When the support area decreased, the earth pressure first increased and then decreased, the corner soil was plastically extruded, and the end earth pressure reached the limit state and then began to decrease; When buoyancy decreased at the same time, the side resistance sharing ratio increased gradually to meet the stress balance of open caisson. RF-4 and RF-5 decreased as the water level decreased, and the amount of decrease was equivalent to the decreased water head. When the blade feet were partially empty, the reaction force monitored by the edge point was mainly buoyancy. The additional stress of the basement at the corner point was greater than that at the edge point, and the wrapping effect was more obvious; the use of corner earth pressure data could be more effectively reflect the force state of the caisson.

With the decrease of water level in the cabin, the soil was prone to plastic failure under the action of the earth pressure difference between the two sides of the blade end, and the surrounding soil had gushed into the cabin. In the process of rapid sinking, the corner earth pressure decreased gradually, which reflecting the process of plastic extrusion of soil at the edge. Due to the thixotropy of soft soil, the side friction and supporting force decreased rapidly, which led to the overbalance and downward movement of open caisson, resulting in rapid subsidence. The strain softening characteristics of high thixotropy and structural silt are the main reasons for the rapid sinking of open caisson ${ }^{[9]}$. After the rapid sinking, the soil support was re-established and gradually stabilized from the unstable state. From the change of the earth pressure at the edge point, it could be seen that the end earth pressure quickly recovered with the increase of the penetration depth of the caisson blade feet.

\subsection{Settling rate}

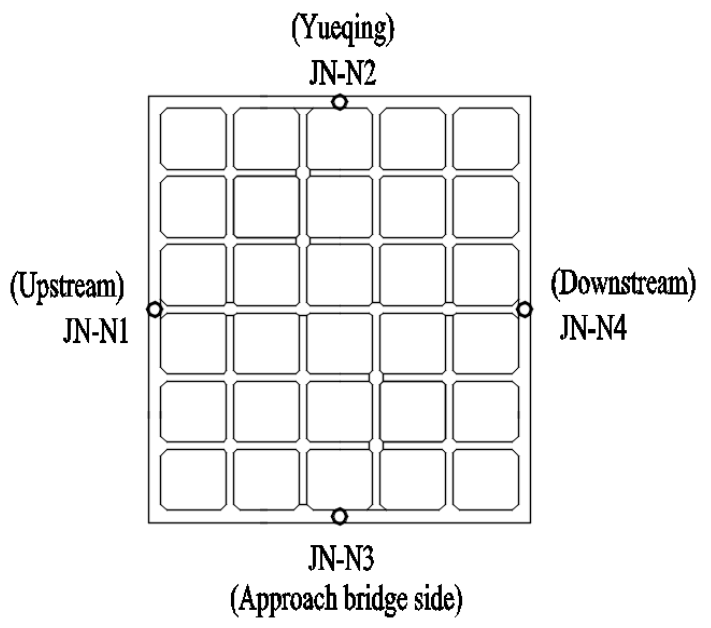

Figure 4. The layout of settlement monitoring.

The layout of the top position measuring points on the top of the caisson is shown in figure 4. The system records the spatial coordinates of the measuring points once in 5 seconds, and can monitor the subsidence. The rapid subsidence rate curves are shown in figure 5 and figure 6 .

The sinking rate(v) in the stagnation stage was less than $1 \mathrm{~cm} / \mathrm{d}$. Before sinking quickly, $\mathrm{V}$ gradually 
increased. When the caisson was unstable, $\mathrm{v}$ increased rapidly and exceeded $2 \mathrm{~cm} / \mathrm{min}$. The fitted sinking rate curve presents a "single peak shape". After the soil support was gradually established, $v$ decayed rapidly and approached zero. The peak sinking rate of JN-N3 on the downstream side of the first rapid sinking was the largest, and $\mathrm{JN}-\mathrm{N} 1$ on the upstream side was relatively the smallest. The downstream side lost stability first, and $v$ decayed first; at that time, the other three monitoring points $v$ hadn't reached the peak rate.

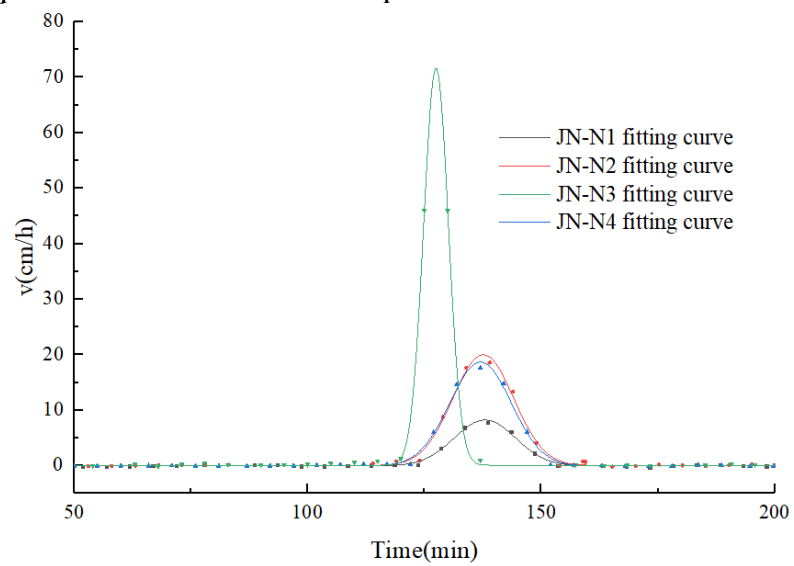

Note: The "0" time in the picture is 0:00 on July 22.

Figure 5. Sinking rate curve in the first rapid sinking.

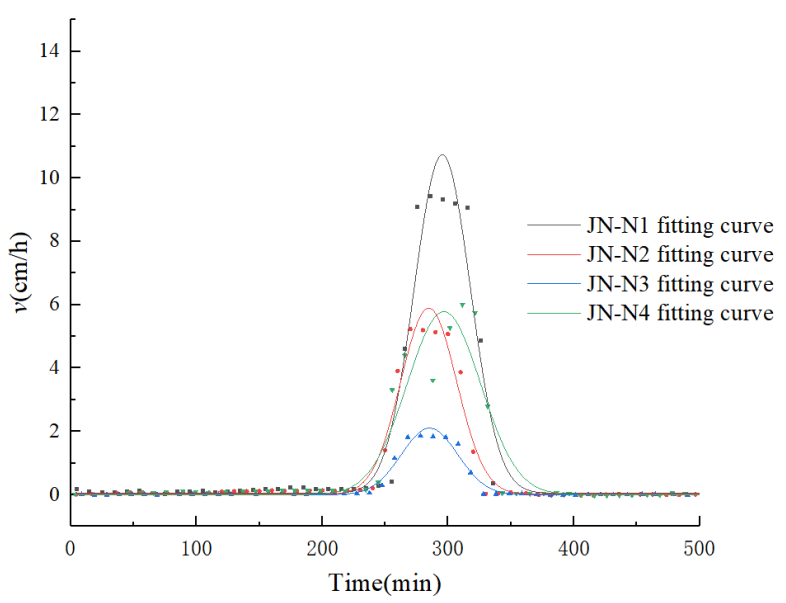

Note: The "0" time in the picture is 0:00 on Sep 26.

Figure 6. Sinking rate curve in second rapid sinking.

The depth of the blade feet before the first sinking and the second sinking is shown in figure 7 and figure 8 . A positive value indicated the depth of the blade feet inserted into the mud surface, a negative value indicated that the blade feet was empty, and the absolute value was the distance from the mud surface to the blade feet.

Before the first rapid sinking, the blade feet of the three outermost continuous compartments in the downstream were in a void state. The supporting area of the mud surface was smaller than that on the upstream side, and the blade feet were located in a silt layer containing cohesive soil, which was more prone to gushing soil. The blade feet on the downstream side were squeezed and destroyed, and the connection of the plastic zone was led to the instability of the downstream side of the influx of soil, inducing instability and failure of the soil in other locations.

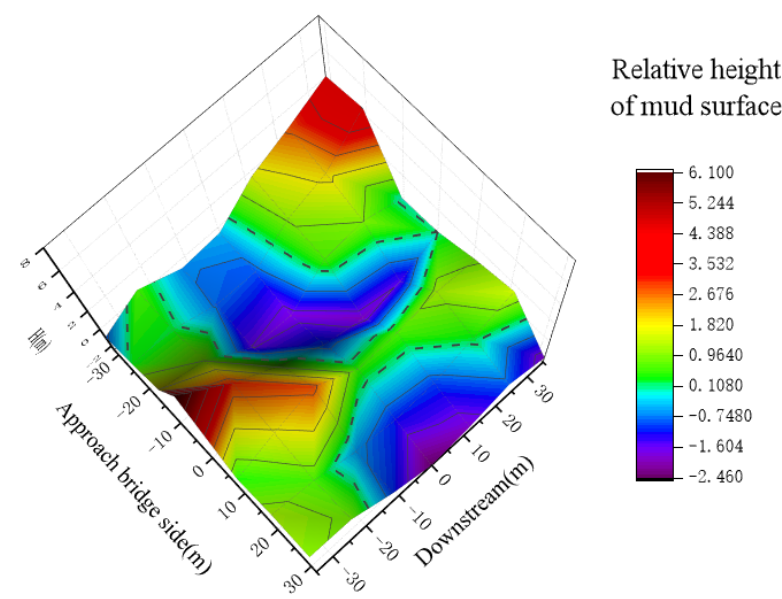

Figure 7. Depth of the blade feet buried before the first time rapid sinking.

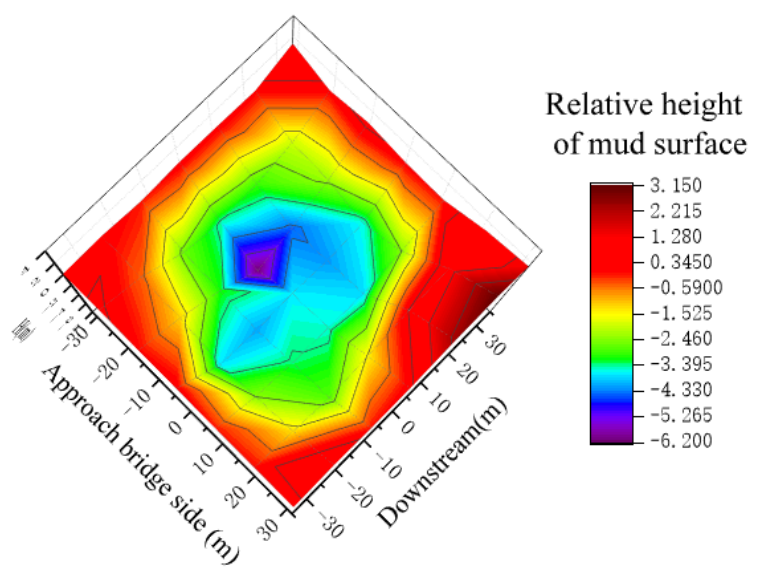

Figure 8. Embedded depth of blade feet before the second rapid sinking.

During the second subsidence, compared with JN-N3, $v$ of JN-N1 and JN-N2 increased rapidly. The side with a large amount of sinking. In other words, the side with a small supporting area of the mud surface, would initiate the sinking first, and end the unstable state at the latest. The period of rapid sinking instability was about 90 minutes, and the $v_{\max }$ was $11 \mathrm{~cm} / \mathrm{min}$. The rapid sinking caused by precipitation, which $v_{\max }$ was smaller than the first time, and the instability time was longer. It had showed that only part of the plastic zone of the soil was destroyed during the precipitation process with reducing of the bearing capacity.

The rapid subsidence can be divided into 4 stages. 1) The stagnation stage, the sinking of the caisson is difficult. 2) The start-up stage, the corner earth pressure decreases, and $v$ gradually increases. 3) The unstable stage, $v$ increases rapidly, and the side with small support area loses stability first. In the process of soil gushing, the support gradually establishes, and the subsidence rate decreases rapidly. 4) In the stable stage, $v$ decays to zero and stagnates again. In the start-up stage, the rapid sinking early warning will have enough time to evacuate people, avoiding the loss of life and property. 


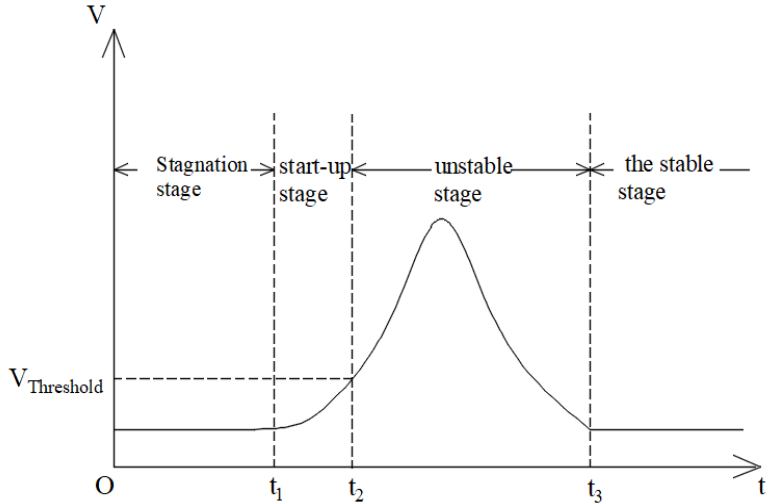

Figure 9. Division of rapid sinking stage.

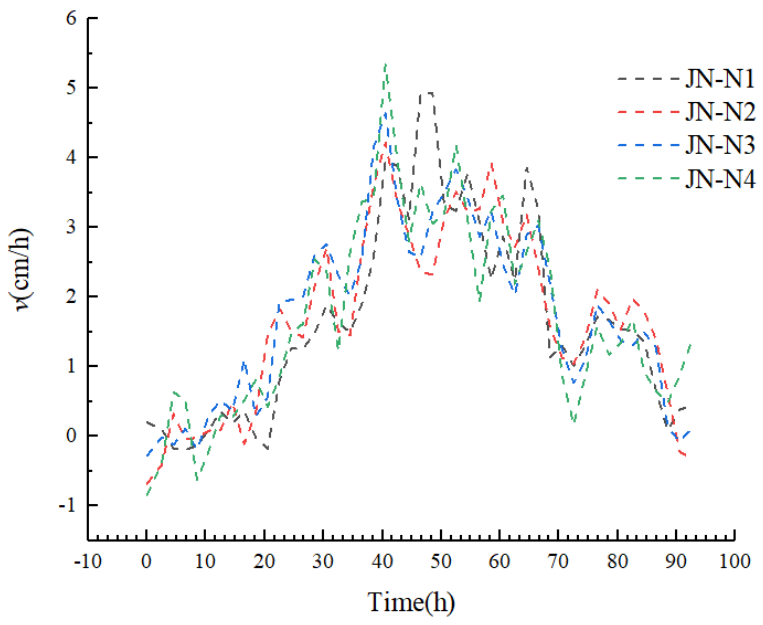

Note: time 0 in the Figure is 20:30 on October 30, 2019.

Figure 10. Sinking rate during dewatering.

The sinking rate from October 30 to November 2, 2019 is shown in figure 10. The curve during dewatering assisted sedimentation is "multi peak", and the $v$ peak valley of each measuring point is not identical, and the sinking well sinks during the swing process. $v$ is less than $5 \mathrm{~cm} / \mathrm{h}$, and the sinking data analysis shows that when $v$ exceeds the threshold value of $5 \mathrm{~cm} / \mathrm{h}$ and lasts for 2 hours, it will start the rapid sinking trend.

\subsection{Early warning mechanism}

Table 1. Sinking warning matrix of classification

\begin{tabular}{|c|c|c|c|}
$\begin{array}{c}\text { Settling } \\
\text { rate } \\
\text { parth }\end{array}$ & 1 & 2 & 3 \\
\hline 1 & $\begin{array}{c}\text { first-level } \\
\text { warning }\end{array}$ & $\begin{array}{c}\text { first-level } \\
\text { warning }\end{array}$ & $\begin{array}{c}\text { secondary } \\
\text { warning }\end{array}$ \\
\hline 2 & $\begin{array}{c}\text { first-level } \\
\text { warning }\end{array}$ & $\begin{array}{c}\text { secondary } \\
\text { warning }\end{array}$ & $\begin{array}{c}\text { three-level } \\
\text { warning }\end{array}$ \\
\hline 3 & $\begin{array}{c}\text { secondary } \\
\text { warning }\end{array}$ & $\begin{array}{c}\text { three-level } \\
\text { warning }\end{array}$ & $\begin{array}{c}\text { three-level } \\
\text { warning }\end{array}$ \\
\hline
\end{tabular}

The end earth pressure and sinking rate can be used for early warning of rapid sinking of open caisson. Limited by the number of measuring points, it can reach the number matrix of early warning points shown in table 1 for hierarchical early warning.

The early warning timeline of rapid sinking is shown in figure 11. The settlement warning was later than the earth pressure warning at the corresponding point, and there was a time difference between them. The earth pressure warning time and settlement warning time of the side with a small supporting area were earlier than those on the other side, and it was more sensitive to dewatering. The above-mentioned early warning mechanism was established after the rapid sinking on July 22, and successfully issued a level three warning four hours early on September 26.

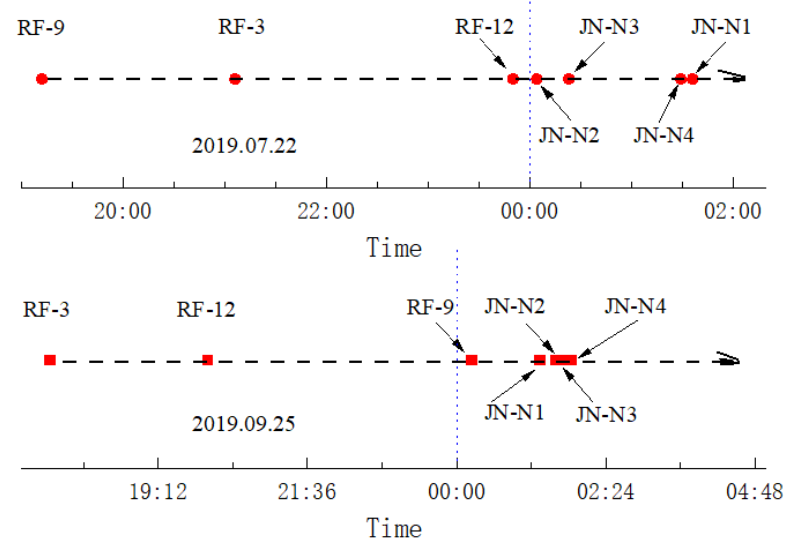

Figure 11. Warning time line of rapid sinking

\section{Mechanism analysis of rapid sinking}

The paper ${ }^{[10]}$ pointed out that in the sinking construction of caisson in saturated sand, severe sand turning can easily lead to rapid sinking. The paper ${ }^{[1]}$ analysed the sinking data of the No.29 caisson of Hutong Bridge and showed that the earth pressure on the outer wall of the caisson increased a few hours before the rapid sinking or sand turning, and after the rapid sinking and sand turning, the earth pressure on the outer wall decreased sharply. In the process of sand turning, the structure of sand was lost, and this structural loss was gradually developed, so the outer wall earth pressure continued to increase; after the rapid sinking, the structure of the sand gradually recovered, and the outer wall earth pressure decreased sharply.

In the first rapid sinking, the blade feet entered the sandy soil layer, the drop in the water level in the tank increased the possibility of soil gushing. There was continuous voiding in the well wall cabin, and the large soil gushing channel caused rapid sinking. Due to the thixotropy of the upper soft soil, its strength decreased rapidly after disturbance, and the side friction resistance decreased rapidly, which was manifested as the softening of the side resistance. The caisson destabilized and sank quickly. Decreasing the water level of the compartment accelerated the process of the end soil pressure increasing to the limit value, and the plastic failure of the soil support.

Combining the construction experience of this project, firstly, it is important to avoid stagnation, and take measures to increase the sinking coefficient or assist 
settlement when stagnant settlement occurs. Secondly, control the depth of the bottom of the pot and the depth of the blade feet to avoid instability of the caisson caused by influx of soil. And finally; it is necessary to strengthen monitoring, timely analysis and early warning to reduce construction safety risks.

\section{Conclusion}

Large caisson constructed in the soft soil layer is prone to rapid sinking during the sinking process. Rapid sinking is often accompanied by partial sinking, which affects construction safety and subsequent construction. There is no relevant early warning mechanism for early warning of rapid sinking. This paper studies the two rapid settlement early warnings of a large land caisson foundation on the south anchorage of a suspension bridge, and proposed to use earth pressure and sinking rate to give early warnings for it, which can be used as a reference for similar projects.

(1) Due to uneven mud suction and uneven stratum distribution, rapid sinking is often accompanied by partial sinking.

(2) The soil at the blade feet is plastically damaged, and the soil pressure at the blade feet decreases after reaching the limit value; after the plastic zone is connected, the gushing soil causes the caisson to instability. The strain softening of high thixotropy and structural sludge and the rapid reduction of side friction are the important reasons for the rapid sinking of open caisson.

(3) The continuous drop of earth pressure at corner points is used as an early warning mechanism for earth pressure, and the sinking rate exceeding the threshold two hours is used as an early warning mechanism for settlement; this dual control mechanism can effectively warn the rapid sinking of the caisson.

(4) In order to avoid rapid sinking, the caisson should firstly be prevented from sinking, and measures to increase the sinking coefficient or assisting settlement should be taken when the sinking is stagnant. Secondly, the depth of the bottom of the pot and the depth of the blade feet should be controlled to avoid the loss of the sinking well caused by the influx of soil. Stability. Finally, monitoring should be strengthened, and data should be analysed and early warning in a timely manner to reduce construction safety risks.

With the development of large-scale monitoring technology and its application in large-scale caisson, the follow-up researches can analyse the mechanism of rapid subsidence from the perspective of other monitoring data, and further improve the early warning mechanism. Secondly, numerical simulation and indoor model tests can be used to study the rapid sinking mechanism and put forward the corresponding early warning mechanisms.

\section{References}

1. Jiang Bingnan. Resistance and suddenly Sinking Monitor research of deep and large open caisson of $\mathrm{Hu}$ Tong Bridge. D. Chengdu: Southwest Jiaotong University, 2016.

2. Chang Dabao. Key techniques of caisson sinking construction process. J. Transportation Science \& Technology, 2011, 04: 41-43.

3. He Qiaoling, Wang Jinguo, Xu Yushen. Study of monitoring of the earth pressure of south anchorage foundation of Taizhou Changjiang River Highway Bridge. J. Science Technology and Engineering, 2013, 13(12): 3514-3519.

4. Zhang Kai, Ma Jianlin, Zhou Hexiang et al. Study on side-wall frictional resistance during open caisson sinking by centrifugal model test. J. Railway Engineering, 2019, 59(06): 28 32.

5. Chen Xiaoping, Qian Pingyi, Zhang Zhiyong. Study on penetration resistance distribution characteristics of sunk shaft foundation. J. Chinese Journal of Geotechnical Engineering, 2009, 26(2): 43-46, 51.

6. Mu Baogang, Wang Yan, Zhu Jianmin et al. Analysis of large caisson sinking Measured Resistance. J. Journal of Civil, Architectural and Environmental Engineering, 2012, 34(S1): 107 115.

7. Li Zongzhe, Zheng Junjie, Fu Qingge. Monitoring and analysis of sinking of super large caisson in deep water. J. Port \& Waterway Engineering, 2009, 17(10): 78-84.

8. Ma Yuangang, Liu Yanfeng, Huang Rui. Study of Mechanism and early warning indexes of abrupt sinking of large open caisson in deep soft clay layers. J. Bridge Construction, 2019, 49(S1): 33-38.

9. Yan Fuyou, Shi Gang. Analysis of limiting soil resistance beneath cutting curb during sinking of open caisson. J. Rock and Soil Mechanics, 2013, 34(S1): 80-87.

10. Zhang Ruijin. On Prevention of problems from caisson sinking. J. China Municipal Engineering, 2006, 2: 56-57.

11. Zhou Jinzhi, He Qi. Stability analysis of sinking for north anchorage caisson of Yingwuzhou Yangtze River Bridge. J. Science Technology and Engineering, 2017, 17(28): 131-136. 